\title{
AGAINST MIRACLES AS LAW-VIOLATIONS: A NEO-ARISTOTELIAN APPROACH
}

\author{
JOEL ARCHER
}

Saint Louis University

\begin{abstract}
Miracles are commonly understood in the way David Hume defined them: as violations of the laws of nature. I argue, however, that the conjunction of Hume's definition with a neo-Humean view of the laws of nature yields objectionable consequences. In particular, the two jointly imply that some miracles are logically impossible. A better way of thinking about miracles, I suggest, is on a neo-Aristotelian metaphysics. On that view, the laws of nature contain built-in ceteris paribus clauses that allow for the possibility of external influences in the natural world. Miracles, understood as instances of external, divine influence, would therefore neither violate the laws of nature nor be instances of those laws. In this respect, neo-Aristotelians have an advantage over neo-Humeans in providing a coherent account of miracles.
\end{abstract}

\section{INTRODUCTION}

According to David Hume, miracles are violations of the laws of nature by God's will. ${ }^{1}$ Hume's definition has profoundly impacted subsequent philosophical and theological discussions on the nature of divine activity in the world. Part of my objective in this essay is to point out the inadequacy of Hume's definition when it is conjoined with a neo-Humean understanding of the laws of nature. ${ }^{2}$ Neo-Humeans typically think of

${ }^{1}$ In his Enquiry Concerning Human Understanding, Hume writes, 'A miracle is a transgression of the laws of nature by the volition of Deity. David Hume, An Enquiry Concerning Human Understanding, in Modern Philosophy: An Anthology of Primary Sources, ed. by Roger Ariew and Eric Watkins (Indianapolis, IN: Hackett Publishing, 1988), pp. 533-600 (p. 537). For this essay, I adopt the usual interpretation of 'transgression' as 'violation'.

${ }^{2}$ For an extended critique of Hume's definition of a miracle in general, see Timothy McGrew, 'Miracles', in The Stanford Encyclopedia of Philosophy, ed. by Edward N. Zalta, 
the laws of nature in terms of (i) an 'exceptionless generalization' view or (ii) a 'best systems' view. I maintain, however, that the conjunction of either view with Hume's definition yields objectionable consequences. Specifically, when conjoined with Hume's definition, the exceptionless generalization view entails that miracles are logically impossible, and the best systems view precludes the possibility of what I call recurrent miracles, i.e. divine activity that is exercised regularly and predictably.

A better way to think about miracles, I suggest, is within a neoAristotelian framework. ${ }^{3}$ According to Neo-Aristotelians such as Alexander Bird, the laws of nature track dispositional properties that are found in nature. ${ }^{4}$ These properties, according to Bird, are subject to what are called finks or masks, i.e. conditions that prevent a disposition from being manifested. ${ }^{5}$ As a consequence, the laws of nature have ceteris paribus clauses built into them: the laws hold only in the absence of finks and masks. Miracles, I suggest, might be seen as cases of divine finks and masks. ${ }^{6}$ On such a view, miracles are not violations of the laws of nature, as Hume believed. Rather, they are unique instances of divine activity that interact with the dispositional capacities found in the world.

The aforementioned ideas are developed and defended in three sections. In section one, I argue that the Humean definition of a miracle conjoined with neo-Humean views of the laws of nature yield the inadequate results mentioned above. In section two, I present Bird's dispositionalist interpretation of the laws of nature and show how miracles might be seen as divine finks and masks. Finally, in section three, I conclude by considering several objections to the proposed account.

Winter 2014, <http://plato.stanford.edu/archives/win2014/entries/miracles/> [accessed 28 April 2015].

${ }^{3}$ For another author writing along similar lines, see Benedikt Paul Göcke, 'Did God Do It? Metaphysical Models and Theological Hermeneutics', International Journal for Philosophy of Religion, Vol. 78, No. 2 (2015), 215-231.

${ }^{4}$ Alexander Bird, Nature's Metaphysics: Laws and Properties (Oxford: Oxford University Press, 2007), p. 2.

${ }^{5}$ Ibid., pp. 25-29.

${ }^{6}$ This is not to say, of course, that divine finks and masks are the exclusive means of divine activity in the world. Divine activity might come in other forms. Part of the point of my exposition is to show that at least a class of miracles might occur in the world without violating the laws of nature, and such activity makes more sense under a neo-Aristotelian interpretation of nature's laws than it does under a neo-Humean interpretation. 


\section{MIRACLES WITHIN NEO-HUMEANISM}

As noted above, Hume considered miracles to be violations of the laws of nature by God's will. One of the main difficulties in understanding Hume on this point is that he spoke little of what the laws of nature are supposed to be. ${ }^{7}$ It is widely recognized, however, that Hume's broader views on causation gave rise to what is known as the Regularity theory of the laws of nature. ${ }^{8}$ According to the Regularity theory, the laws of nature express patterns of modally disconnected events in the world. David Lewis compares the regularity of the world's events to a vast glass mosaic: from a distance, one can see patterns emerge in the entire mosaic; nevertheless, these patterns are merely the sum of disconnected pieces of glass. ${ }^{9}$ Similarly, laws of nature are patterns of modally disconnected events. Neo-Humeans since Hume have devoted considerable effort in formulating more precise versions of the Regularity theory. Part of my project, therefore, will be to explore what neo-Humeans have said concerning the laws of nature.

Neo-Humean theories about the laws of nature come in two broad varieties: the exceptionless generalization view and the best systems view. I will now examine both and indicate the consequences of conjoining each with Hume's definition.

\subsection{The Exceptionless Generalization View}

The exceptionless generalization view, as its name implies, states that the laws of nature admit of no exceptions. D. H. Mellor explains that on this view, 'law statements [...] are (or at least entail) 100\% generalizations of the form "All $\alpha$ s are $\beta s " .{ }^{10}$ As a result of empirical inquiry, humans are able to make universal generalizations concerning the natural regularities they observe in the world. If some event $\mathrm{E}$ occurs that does not conform to a present universal generalization $G$, we construct a new universal generalization $G$ ' that accounts for $E$. In other words, we claim that $G$ did not truly reflect the laws of nature. Ultimately, there is a universal

${ }^{7}$ David Armstrong, What is a Law of Nature? (Cambridge: Cambridge University Press, 2009), p. 4.

8 Ibid.

${ }^{9}$ David Lewis, Philosophical Papers Volume II (New York: Oxford University Press, 1986), p. ix.

${ }^{10}$ D. H. Mellor, Matters of Metaphysics (Cambridge: Cambridge University Press, 2007), p. 162. 
generalization $\mathrm{G}^{*}$ that reflects regularities exceptionlessly and therefore represents the laws of nature without aberration. ${ }^{11} \mathrm{G}^{*}$ might turn out to be a very complex set of descriptions; yet once it is established, there are no exceptions to $\mathrm{G}^{*}$.

Hume's definition of a miracle, however, yields objectionable consequences when conjoined with the exceptionless generalization view. For their conjunction would render miracles logically impossible. If we accept that miracles are violations of the laws of nature and that the laws of nature are nothing but exceptionless regularities, it follows that miracles are violations of natural regularities, which on the exceptionless regularity view are impossible. ${ }^{12}$ Christopher Hughes puts the argument another way: 'If miracles are possible, then either miracles are not violations of the laws of nature, or the laws of nature are not (necessarily) exceptionless.'13 But, as we have seen, neither of Hughes's disjuncts is acceptable to the advocate of both the exceptionless generalization view and Hume's definition. ${ }^{14}$ I suggest that the foregoing argument's conclusion, i.e. that miracles are logically impossible, ought to be undesirable to both theists and most atheists. Theists, I presume, believe that miracles actually occur (or have occurred in the past). And most atheists typically assert that although miracles do not in fact occur, their occurrence is nonetheless logically possible. ${ }^{15} \mathrm{E}$. J. Lowe has conjectured that Hume himself probably did not hold to an exceptionless

${ }^{11}$ Stephen Mumford, 'Normative and Natural Laws', Philosophy, Vol. 75, No. 292 (2000), 265-82 (p. 276). Popper describes this view in Karl Popper, The Logic of Scientific Discovery (New York: Routledge, 1992), p. 62. As is well known, Popper's point is that one exception is all that is needed to falsify a law.

${ }^{12}$ It is important to note that on the present view the impossibility of miracles (as defined by Hume) does not imply that God cannot act in the world. Rather, it means that if God were to act, his act would not be a miracle but instead a part or instance of the laws of nature. This consequence seems immediately counterintuitive, as I will suggest later in the paper.

${ }^{13}$ Christopher Hughes and Robert M. Adams, 'Miracles, Laws of Nature and Causation', Proceedings of the Aristotelian Society, Vol. 66, No.2 (1992), 179-205 \& 20724, (p. 186).

${ }^{14} \mathrm{I}$ am in agreement with Steven Mumford on this point. See Mumford, 'Normative and Natural Laws', p. 269.

${ }^{15} \mathrm{I}$ admit that the above argument would not be persuasive to the type of atheist who grants that miracles are logically impossible to begin with. The conjunction of the exceptionless generalization view and Hume's definition would entail their conclusion. I suspect, however, that such atheists are rare. Most, it seems, acknowledge at least the possibility of miracles even if none occur in the actual world. In any case, my arguments 
generalization view of the laws of nature. ${ }^{16}$ For if he had, then Hume's later project of arguing that no testimony could be sufficient to establish a miracle would be trivial: one could simply rule out miracles a priori.

Thus, the neo-Humean confronts a challenge: how might she understand miracles in a way that does not render the occurrence of miracles logically impossible? In one of his papers, Lewis puts forward a position that would answer this challenge. The approach Lewis takes is to modify the term 'miracle' to mean a violation of the laws of nature not of this world, but of some other possible world. More generally, consider two worlds, $\mathrm{w}_{1}$ and $\mathrm{w}_{0}$. A miracle might take place in $\mathrm{w}_{1}$, where the miracle is a violation of the laws of nature not of $\mathrm{w}_{1}$ but of $\mathrm{w}_{0}$. Lewis states:

When I say that a miracle takes place at $\mathrm{w}_{1}$, I mean that there is a violation of the laws of nature. But note that the violated laws are not the laws of the same world where they are violated [...] a miracle at $\mathrm{w}_{1}$, relative to $\mathrm{w}_{0}$, is a violation at $\mathrm{w}_{1}$ of the laws of $\mathrm{w}_{0} \cdot{ }^{17}$

In other words, Lewis supposes that violations of the laws of nature are possible but only relative to different worlds in which different laws hold.

What are we to make of this position? I think Lewis's modification does not solve the problem without yielding absurd consequences. I will consider two main points. First, Lewis's modification of the term 'miracle' would still entail that any event - no matter how unusual or seemingly supernatural - is a part of the laws of nature in the actual world. Suppose that my friend comes up to me and loudly declares, 'I command you to levitate.' Suddenly, I begin to hover three feet above where I previously stood. Call the world in which this event takes place the 'levitation-world'. If Lewis is correct, such an event in the levitationworld would be a miracle relative to some other possible world (like ours, presumably) in which no one ever levitates. But it would still remain the case that relative to the levitation-world, the event would be a part of the laws of nature. No laws of nature are violated in the levitation-world, for the laws (on the exceptionless generalization view) subsume all events.

are directed to those who hold that miraculous divine interventions are, if not actual, at least logically possible. Thanks to Kevin Timpe for comments here.

${ }^{16} \mathrm{E}$. J. Lowe is perplexed by the unsatisfactory conclusion of the Humean argument which he regards as 'too easy'. See his 'Miracles and Laws of Nature', Religious Studies, Vol. 23, No. 2 (1987), p. 263, p. 270.

17 David Lewis, Philosophical Papers Volume II (New York: Oxford University Press, 1986), pp. 44-45. 
The levitation-event might be surprising (especially if the levitationworld is like ours up until the levitation-event), but it would it would not thereby be an exception to the laws of nature. ${ }^{18}$ This consequence, however, seems immediately counterintuitive. The correct response from the denizens of levitation-world would be to think that my friend has some mysterious, supernatural ability to bring about an event beyond the laws of nature that are operative in that world. But, as we have seen, the exceptionless generalization view precludes that possibility.

Second, construing miracles as law-violations in other possible worlds yields an even more absurd consequence, namely, it makes the occurrence of miracles too easy. Consider: presumably there is a possible world $\mathrm{W}$ in which everyone on earth suddenly levitates three feet above where they are located. But then the fact that in the actual world we are not levitating would count as a miracle relative to world W. It would therefore be a miracle that everyone does not levitate in the actual world. Such cases can be generalized: any event in the actual world that diverges from the laws in other worlds would count as a miracle. In light of these counterintuitive consequences, I suggest that Lewis's modification does not help the exceptionless generalization view. Rather, the Humean should stick to Hume's original conception of a miracle: a miracle in $\mathrm{W}$ is a violation of the laws of nature in $\mathrm{W}$. But then we are brought back to our original conclusion: Hume's definition conjoined with the exceptionless generalization view entails that miracles are logically impossible.

\subsection{The Best Systems View}

A more sophisticated version of the Regularity theory, however, is open to neo-Humeans. It is known as the 'best systems' view, most prominently defended by Lewis and David Ramsey. According to this view, not every regularity counts as a law of nature. Rather, laws of nature are to be understood as the best systematization of the regularities, where 'best' is understood in terms of postulating the fewest possible axioms from which one can derive the maximum number of events in the world. ${ }^{19}$ In other words, laws of nature on the best systems view are determined

${ }^{18}$ The laws of nature on the universal generalization are said to be observerindependent. In other words, they lack epistemic conditions on them. Thus, the fact that some particular event might be surprising or unpredictable given one's current knowledge of the world has no bearing on the nature of the laws themselves on this view.

${ }^{19}$ Robert Adams considers this a possibility for the Regularity theorist. See Adams and Hughes, 'Miracles, Laws of Nature and Causation', 179-205 \& 207-24, (p. 212). 
by a balance of their strength and simplicity in accounting for the vast mosaic of disconnected qualities in the world.

Is it possible to understand Humean miracles within this best systems approach? It appears so, at least initially. On such a view, miracles would be events which lie 'outside' the regularities entailed by the laws of nature. In his book The Concept of a Miracle, Richard Swinburne, although himself not a neo-Humean about the laws of nature, ${ }^{20}$ provides a way in which one might do this. He claims that 'One must [...] distinguish between a formula being a law and a formula being (universally) true or being a law which holds without exception. ${ }^{21}$ Embracing this distinction, Swinburne claims that miracles might suitably be called violations of the laws of nature where the laws of nature do not imply universality (exceptionlessness). Such a model might work as follows. Consider some purportedly miraculous event $\mathrm{E}$ and a law of nature $\mathrm{L}$ (both in the same world). We saw earlier that on the exceptionless generalization view, $\mathrm{E}$ would necessarily be subsumed under a further set of laws $\mathrm{L}_{1}$. But this is not the case on the best systems approach. It is not necessarily true that E can be subsumed under a new set of laws. Swinburne explains:

[...] L will have to be retained as a law of nature and $\mathrm{E}$ regarded as a non-repeatable counter-instance to it, if any proposed rival formula $\mathrm{L}_{1}$ were too much more complicated than $\mathrm{L}$ without giving better new predictions, or predicted new phenomena unsuccessfully where L predicted successfully. ${ }^{22}$

Using the criterion Swinburne provides, it seems that there is logical space for events outside the laws of nature as long as these events are sufficiently irregular such that incorporating them into a new set of laws would make the resulting laws less adequate in terms of simplicity and strength.

While the best systems view is certainly an advance over the exceptionless generalization view, I maintain that it suffers from at least one major defect, namely, it excludes the possibility of what I call recurrent miracles. Recurrent miracles are a species of divine action in the world that occur in a regular, predictable manner and that satisfy the

\footnotetext{
${ }^{20}$ From a recent personal conversation. Also, see Richard Swinburne, Mind, Brain, and Free Will (Oxford: Oxford University Press, 2013), pp. 125-40.

${ }^{21}$ Richard Swinburne, The Concept of Miracle (New York: Macmillan, 1970), p. 30. Italics in original.

${ }^{22}$ Ibid., p. 29.
} 
conditions necessary to be included in the best system of natural laws. For instance, suppose that every time I release a pen in mid-air, God causes the pen to fly up into space instead of falling to the ground. Suppose this phenomenon occurs not just to me but to everyone in a regular, predictable manner. Of course, this scenario is logically possible. If this were to occur, however, the best systems view would have to categorize such behaviour as an instance of a law of nature. For suppose that it did not: there would then be a vast range of phenomena that the axioms of the best system would not account for. Thus, these recurrent miracles would have to be included as part of the laws of nature rather than being violations of them. But then our previous problem reappears: given Hume's definition, recurrent miracles would not be miracles at all. In other words, the best systems view implies that recurrent miracles, as I have defined them here, are logically impossible.

Again, this conclusion ought to be problematic for those (theists and most atheists) who think that recurrent miracles are logically possible. Indeed, some Christians hold that recurrent miracles are not only logically possible but also actual. For instance, some maintain that the real transformation of the bread and wine into the body and blood of Christ takes place in a regular, predictable manner, and under specified conditions. ${ }^{23}$ Some Christians think that God miraculously unites a person's soul to his or her body at the moment of conception. Such miracles would again be regular and predictable under specified circumstances. ${ }^{24}$ These, I suppose, might be cases of actual, recurrent miracles. Nevertheless, my claim is weaker: I contend only that such miracles are possible, and my thesis goes through on this much weaker assumption.

The conclusion I gather from the discussion of the best systems view is this: the account makes logical room for miracles as long as such events are highly irregular and do not fit within the best system of laws. It is perfectly possible, however, that recurrent miracles should

${ }^{23}$ For instance, in Summa 3, question 76, article 8, Aquinas writes concerning the Eucharist: 'It remains to be said, that, while the dimensions remain the same as before, there is a miraculous change wrought in the other accidents, such as shape, colour, and the rest ... And, as was said already, this is not deception, because it is done "to represent the truth" namely, to show by this miraculous apparition that Christ's body and blood are truly in this sacrament.' Italics mine. Thomas Aquinas, Summa Theologica, available at: <http://www.newadvent.org/summa/4076.htm> [accessed September 4, 2014].

${ }^{24}$ I have Luis Pinto de Sá to thank for these examples. 
exist. But when conjoined with Hume's definition of a miracle, the best systems view entails that they cannot exist. Thus, we are landed back with the same problem afflicting the exceptionless generalization view. Yet surely this is wrong, for it is entirely possible that God might perform recurrent miracles.

To summarize the first section, I want to draw attention to the deeper problem that, I think, afflicts the Humean position regarding miracles and the laws of nature. When the Humean denies the existence of real causal connections and intrinsic dispositions within nature, she is left trying to build 'laws' out of the regularities the world's vast array of disconnected events. The problem, as I hope to have shown, is that there might be miracles that fit any such law-construction which the Humean puts together. The upshot is that miracles become parts or instances of the laws of nature. When conjoined with Hume's definition of a miracle, of course, such miracles are ruled out by definition. This unwanted consequence strongly suggests that we should look elsewhere for a more sensible account of miracles.

\section{DISPOSITIONALISM AND MIRACLES}

In this section, I propose a different, more intuitive way to think of miracles within the context of a neo-Aristotelian metaphysics. The view I have in mind assumes a metaphysical position regarding the nature of properties known as dispositionalism. The roots of dispositionalism can be traced back to Aristotle, and its recent defenders include Alexander Bird, Stephen Mumford, Brian Ellis and Caroline Lierse, E. J. Lowe, Sydney Shoemaker, and others. ${ }^{25}$ For the purposes of this paper, I will regard Bird's view as representative of the dispositionalist account.

Dispositionalism, according to Bird, is the view that all properties have their particular dispositions essentially; for an entity E to have a property means that $\mathrm{E}$ is disposed to bring about a particular manifestation (or manifestations) under a certain stimulus. ${ }^{26}$ Further, that particular property has those exact dispositions in all possible worlds (at least in

${ }^{25}$ Alexander Bird, 'The Dispositionalist Conception of Laws', Foundations of Science, 10 (2005), 353-70; Mumford, 'Normative and Natural Laws', pp. 265-82; Brian Ellis and Caroline Lierse, 'Dispositional essentialism', Australasian Journal of Philosophy, 72 (1994), 27-45; Lowe, 'Miracles and Laws of Nature', pp. 263-78; Sydney Shoemaker, Identity, Cause, and Mind (Cambridge: Cambridge University Press, 1984).

${ }^{26}$ Alexander Bird, 'The Dispositionalist Conception of Laws', pp. 354-55. 
those in which the property is instantiated). For example, electrons have the property being negatively charged and, by virtue of this property, have the essential disposition to repel other negatively charged objects. The conditional analysis of a disposition can be represented as:

(CA) $\forall \mathrm{x}(\mathrm{Dx} \leftrightarrow(\mathrm{Sx} \square \rightarrow \mathrm{Mx}))$

where $\mathrm{D}$ is a disposition, $\mathrm{S}$ a stimulus, and $\mathrm{M}$ a manifestation. This biconditional states that $\mathrm{x}$ has a certain disposition $\mathrm{D}$ just in case if $\mathrm{x}$ were under a stimulus $S$, then $x$ would manifest $M$. The laws of nature, in turn, are derivable from the nature of properties. From (CA), Bird is logically able to arrive at

$$
\forall \mathrm{x}((\mathrm{Dx} \& \mathrm{Sx}) \rightarrow \mathrm{Mx})
$$

which is the statement of the law of nature. ${ }^{27}$ And since the dispositionalist asserts that properties have their dispositions essentially, Bird concludes that laws of nature, if they track the essences of dispositions, will be metaphysically necessary. ${ }^{28}$

Bird soon recognizes, however, that (L) is defective as it stands. For an entity might have a dispositional property and yet fail to yield its manifestation when it is appropriately stimulated. Bird uses the example of a vase that has the dispositional property $\mathrm{F}$, being fragile. Under normal circumstances, a vase that has F will break when struck with a hammer. Suppose that this particular vase has $\mathrm{F}$ but that when it is struck with a hammer, the strike instantly causes the vase to heat up thereby preventing the vase from breaking. ${ }^{29} \mathrm{C}$. B. Martin has labelled this type of disposition finkish. ${ }^{30}$ Alternatively, to use Lewis's example, suppose that at the very instant the vase is struck with a hammer, a powerful wizard casts a spell on the vase causing its internal structure to become rigid; as a result, the vase does not break. In this case, the wizard has 'finked' the vase. Before the vase is struck, it has the intrinsic disposition to break when struck. Yet it is false that if the vase were struck, then it would break. Both of the above examples provide counterexamples to (L).

Consider, as another example, the hemlock responsible for killing Socrates. The hemlock has the dispositional property of being deadly when ingested. Yet, suppose Socrates takes an antidote immediately after

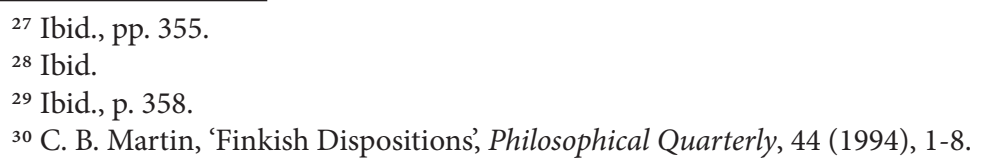


the poisonous ingestion; as a result, he does not die from the hemlock. Do we conclude that the hemlock lacked the property being deadly when ingested? No. We say that although the hemlock did have that dispositional property the antidote introduced an external feature that prevented the disposition from being manifested. Bird refers to such a feature by the technical term antidote, which is also known as (and which I will refer to from now on as) a mask.

Therefore, we can now see that any dispositionalist account needs to describe the laws of nature in the absence of finks and masks. Bird does this by refining (L) and introducing a ceteris paribus clause into the formulation: ${ }^{31}$

(L') $\quad[\forall \mathrm{x}((\mathrm{Dx} \& \mathrm{Sx}) \rightarrow \mathrm{Mx})$, so long as D’s finks and masks are absent]

Under this construction, the laws of nature are consistent with dispositions' existing while not bringing about their characteristic manifestations.

Given these conceptual resources, I suggest that there can be a coherent understanding of miracles within the metaphysical framework of dispositionalism. ${ }^{32}$ On such a view, miracles do not violate the laws of nature; rather, they are events whose causal source lies outside the dispositional capacities found in the world. ${ }^{33}$ Some of God's miraculous actions in the world would be cases of divine finks and masks. He would

${ }^{31}$ Alexander Bird, Nature's Metaphysics, p. 60.

${ }^{32}$ For an excellent exposition of this view, see Toby Handfield, 'Dispositional Essentialism and the Possibility of a Law-Abiding Miracle', The Philosophical Quarterly, Vol. 51, 205 (Oct., 2001), 484-94. Handfield shows how miracles are law-abiding within the framework of dispositional essentialism. My approach takes some of these same ideas and applies them specifically to theistic miracles, such as the resurrection. In particular, my aim is to show how the dispositional essentialist view regarding miracles is superior to the Humean regularity view.

${ }^{33}$ At this point, I might be accused of asymmetry in my attack on neo-Humeanism and proposal of neo-Aristotelianism. For while I argue that violations (or at least certain violations) of the laws of nature are impossible on the neo-Humean account, the same is true of the dispositional account. To violate a law on the dispositional account is impossible because the laws are metaphysically necessary. However, as I explained earlier, the Humean is left with only one equally implausible option: the view that miracles are parts (or instances) of the laws of nature. By contrast, the dispositionalist is able to distinguish events which are neither violations nor parts of the laws of nature. This third option - that miracles are divine interventions which neither violate the laws of nature nor are subsumed by the laws - is unavailable to the neo-Humean. 
have empirical effects in the world none of which would alter or break the laws of nature. ${ }^{34}$

Consider a couple of examples. Suppose we reduce the entire event of the Red Sea's ${ }^{35}$ parting to a couple water molecules that have a natural disposition to attract each other through the process of cohesion. Each of the molecules has the dispositional property of being attracted to other water molecules in close proximity. Now, when God intervenes, he causes the proximate molecules to separate rather than to unite. Thus, the molecules miraculously separate since the disposition of the molecules to attract is not manifested. In this case, God's external influence is a mask in the system. And since, according to (L'), laws of nature require dispositions to yield their manifestations only in the absence of finks and masks, the miracle of the parting water molecules occurs without altering or violating the laws of nature.

Consider another example. When human beings die, their bodies have the disposition to remain dead, to decompose, etc. It is true, then, that in the absence of finks and masks, the laws of nature preclude a dead man's body coming back to life. But, suppose that in the case of Christ's post-crucifixion body, God intervenes in the world by introducing a divine fink. He changes the biochemical structure of Christ's body such that it does not manifest the usual dead-body dispositions. Such a miracle would not count as a breaking of the laws of nature because the dispositionalist claims that the laws proscribe men from resurrecting from the dead in the absence of finks and masks. Lewis's sorcerer casts a spell on the vase such that it does not manifest its fragile dispositions when struck. Similarly, God might change the structure of Christ's body so that his body's ordinary, dead-person dispositions are not manifested. Once again, such a miracle would be consistent with the laws of nature as formulated in (L').

Further, the dispositionalist is easily able to account for recurrent miracles: finks and masks might occur an unlimited number of times, regularly and predictably, without violating any laws of nature. By contrast, on the best systems view, recurrent miracles must be incorporated into the best system of laws and therefore become parts of the laws themselves.

${ }^{34}$ As I mentioned in footnote 6, I do not mean to imply that this is the exclusive way that God might act in the world. Divine activity might come in many forms, and what I am describing is simply one of them.

${ }^{35}$ Or perhaps more accurately, the Sea of Reeds. 
In sum, I have sketched a way of thinking about miracles that, in my mind, is an advance over the Humean way of understanding them. By introducing dispositions into the structure of the world, the neoAristotelian has the conceptual resources to think of miracles as events that occur beyond the natural dispositions of objects. The laws of nature track the nature of dispositions and therefore do not depend - unlike the Humean account - on constructing laws out of regularities.

\section{SEVERAL OBJECTIONS}

I will now consider four objections to the account I have proposed. First, one might worry that the possibility of recurrent miracles suggests that we might not be able to identify such regular events as miracles. For if God regularly finks or masks a certain disposition, we might confuse the miracle with a law of nature. Call this the epistemic problem. A few points in response. First, I think the dispositionalist will have to bite the bullet and acknowledge this possibility. But while this problem is merely an epistemic problem on the dispositional view, it is a much worse problem on the Humean account. The Humean account entails, as I have argued, that recurrent miracles are logically impossible. By contrast, the dispositionalist will, at worse, claim that we cannot know that a recurrent miracle has occurred. Even in the worst case scenario, therefore, the dispositionalist's problem is less acute. Second, we might in fact be able to know which miracles are recurrent by independent means. Those who place epistemic authority on divine revelation or tradition might have a means of knowing, for example, that transubstantiation is a recurrent miracle rather than a law of nature. Third, there does not seem to be any good a priori reason to think that humans should expect to be able to identify all recurrent miracles. Perhaps God has motives for keeping at least some recurrent miracles hidden. For these reasons, I do not think the epistemic problem is compelling.

A second worry is that finks and masks might be the results of our epistemic limitations regarding fundamental properties. Suppose - the objection goes - that the laws of nature contain ceteris paribus clauses that govern higher-order, derivative properties (e.g. fragility or the property of being poisonous) but that such clauses do not apply to fundamental properties (e.g., negative charge). Bird, for instance, maintains that finkish dispositions do not exist at the fundamental level and that it is 
possible that masks do not either. ${ }^{36}$ If this is right, then the problem is that God has no 'room' to intervene at the fundamental level in the form of divine finks or masks. And if we further suppose that higher-order, derivative properties are ultimately reducible to fundamental ones, then the worry might be that God cannot intervene in this way at any level.

A couple of points can be made in response to this objection. First, even if the fundamental laws of nature contain no ceteris paribus clauses, this does not necessarily imply that higher-order laws lack them as well. The implication would follow only if one were to assume reductionism or eliminativism about the laws of nature. However, there are strong reasons for thinking that such inter-level reductionism is misguided. ${ }^{37}$ Second, while I grant along with Bird that finkish dispositions cannot apply to fundamental properties (a fink works by altering the causal basis of a disposition; and fundamental properties, by definition, do not have a causal bases), the story is different regarding masks. There is nothing internally inconsistent about masking a fundamental disposition. Bird believes that it is ultimately an empirical matter whether there are dispositions sensitive to masks. But given that the existence of fundamental masks is not metaphysically impossible, there is nothing incoherent about the idea that some fundamental disposition $\mathrm{D}$ toward a manifestation $\mathrm{M}$ might be masked by God. Therefore, this objection does not constitute a persuasive argument against the present account.

A third objection comes from considerations offered by Robert Adams. ${ }^{38}$ Although Adams is sympathetic to an account similar to what I have sketched, he provides the following worry to the possibility of divine finking and masking. ${ }^{39}$ Consider some entity $\mathrm{X}$ with a certain set of dispositional properties. If God has the power to fink/mask some of X's dispositions, then presumably he has the power to fink/mask all of X's dispositions for a certain period of time (say, an hour). Suppose that were the case; it is then hard to see (a) how X could remain in existence without manifesting any of its dispositions, and (b) how X could persist

\footnotetext{
${ }^{36}$ Alexander Bird, Nature's Metaphysics, pp. 60-65.

${ }^{37}$ For instance, this is one of the main points put forward by John Dupré and Nancy Cartwright. See John Dupré, The Disorder of Things (MA: Harvard University Press, 1993). See also Nancy Cartwright, The Dappled World: A Study of the Boundaries of Science (UK: Cambridge University Press, 1999).

${ }_{38}$ This same objection receives a similar response from Benedikt Paul Göcke. See Göcke, 'Did God Do It?', p. 12.

${ }^{39}$ Adams and Hughes, 'Miracles, Laws of Nature and Causation', pp. 221-23.
} 
over time if there is a certain period (an hour) in which it manifests none of its dispositions. ${ }^{40}$

Answering (a), I will assume, is sufficient for answering (b), for the worry behind (b) is that X does not persist through time because X's identity depends on a continuity of the manifestation of X's dispositions over time. A couple points can be made in response to Adams's worry. First, if God were to fink/mask all of a thing's dispositions, I am not certain it would have the consequences that Adams envisions. For while a thing's identity might depend on its possessing certain properties, it is not obvious that its identity depends on its manifesting those properties. Consider a grain of salt, for instance, which has certain properties: the disposition to dissolve in water, the disposition to cause a salty taste in my mouth, and the disposition to appear to have a white colour. If such dispositions were entirely removed, then Adams is correct: we might wonder how the grain of salt can legitimately be called a grain of salt. However, suppose the grain of salt retains the dispositions even though they are finked/ masked. There is nothing conceptually incoherent, I suggest, in thinking that this grain of salt should exist even if its dispositions - to dissolve in water, to produce a salty taste, to produce a white 'look' - are temporarily finked/masked. Second, even if I am wrong about my first point, the dispositionalist might respond that while God might have the ability to fink/mask all of X's dispositions, he might in fact refrain from doing so precisely for that reason: doing so would make X go out of existence (that is, assuming that Adams's conclusion is correct). Thus, God, as a matter of contingent fact, might not engage in the total finking/masking that Adams imagines. In sum, I think Adams worries, though important, are not sufficient to undermine the dispositionalist account of miracles that I have offered.

Finally, one might wonder whether the laws of nature are such that the ceteris paribus clause ought to include only natural finks and masks and exclude supernatural ones. In other words, one might think that the laws should take into account possible external interference only from the dispositions of natural things instead of actions from God. In

40 At the end of his article, Adams hints at a possible solution that involves the Thomistic idea that there is one fundamental disposition, the liability to be affected by God, that cannot be obstructed by God and which grounds the continued existence of an entity. While this might be a possibility, my response to Adams's objection will not invoke the existence of such a fundamental disposition. 
response, I agree with Toby Handfield that such a restriction on the laws of nature would be entirely arbitrary. ${ }^{41}$ What justification can be offered for the restriction of the laws to only natural finks and masks? It is hard to see how the restriction could be empirically justified, at least in a nonquestion begging way; and there is certainly no a priori reason to think that such supernatural interventions are impossible. Thus, the denial of the possibility of divine finks and masks is as strong as the denial of the possibility of miracles in general. Unless the objection begs the question against the dispositionalist account of miracles, I conclude that it lacks any force.

\section{CONCLUSION}

I have argued that the Humean definition of miracles is unsatisfactory given a neo-Humean Regularity theory about the laws of nature. Both primary versions of the Regularity theory - the exceptionless generalization view and the best systems view - entail that at least some miracles are logically impossible. This is an unwanted result for theists and atheists who affirm the logical possibility of miracles. By contrast, within the neo-Aristotelian metaphysics of dispositionalism one can think of miracles not as violations of the laws of nature but as divine activity that interacts with the dispositional capacities in the natural world. Miracles in the form of divine finks and masks would be entirely consistent with laws of nature since those laws contain built-in ceteris paribus clauses. In this regard, therefore, the neo-Aristotelian view makes better sense of miracles than the neo-Humean account does. ${ }^{42}$

${ }^{41}$ Handfield, 'Dispositional Essentialism', p. 490. Handfield maintains that the dispositionalist might simply deny that determinism regarding the laws of nature is possible. This is essentially the same point I'm making with respect to divine intervention in the world.

42 A special thanks for valuable comments from Eleonore Stump, Robert J. Hartman, Andrew Pinsent, Vincent Archer, and an anonymous reviewer. In addition, this paper received valuable feedback from audiences at the Ian Ramsey Centre for Science and Religion at Oxford University and at a summer seminar in Analytic Theology hosted by the University of Innsbruck. 